\title{
A PRIMARY ACOUSTIC STARTLE CIRCUIT: LESION AND STIMULATION STUDIES ${ }^{1}$
}

\author{
MICHAEL DAVIS, ${ }^{2}$ DAVID S. GENDELMAN, MARC D. TISCHLER, AND PHILLIP M. GENDELMAN \\ Yale University School of Medicine, The Connecticut Mental Health Center, New Haven, Connecticut 06508
}

Received March 25, 1981; Revised January 29, 1982; Accepted February 5, 1982

\begin{abstract}
The latency of the acoustic startle reflex in the rat is $8 \mathrm{msec}$, measured from tone onset to the beginning of the electromyographic response in the hindleg. This extremely short latency indicates that only a few synapses could be involved in some primary acoustic startle circuit. Acoustic startle is being used as a model system for studying habituation, sensitization, prepulse inhibition, classical conditioning, fear or anxiety, and drug effects on behavior. The present study attempted to delineate a short latency acoustic startle circuit, since this would provide critical information for further study in all of these areas.

Bilateral lesions of the ventral cochlear nucleus, which receives the primary auditory input, abolish acoustic startle. Electrical, single pulse stimulation of the ventral cochlear nucleus elicits startle-like responses with a latency of about $7 \mathrm{msec}$. Bilateral lesions of the dorsal and ventral nuclei of the lateral lemniscus, which receive direct input from the ventral cochlear nuclei, abolish acoustic startle. Electrical stimulation of these nuclei elicits startle-like responses with a latency of about 6 msec. Bilateral lesions of ventral regions of the nucleus reticularis pontis caudalis, which contain cell bodies that give rise to the reticulospinal tract, abolish acoustic startle. Electrical stimulation of these points elicits startle-like responses with a latency of about 5 msec. Reaction product from horseradish peroxidase iontophoresed into this area is found in the nuclei of the lateral lemniscus.

In contrast, lesions of the dorsal cochlear nuclei, vestibular nuclei, nucleus reticularis pontis oralis, nucleus reticularis gigantocellularis, and dorsal regions of the nucleus reticularis pontis caudalis fail to abolish acoustic startle. Also, "startle" cannot be elicited electrically from these areas.

The data suggest that a primary acoustic startle circuit in the rat consists of: auditory nerve, ventral cochlear nucleus, nuclei of the lateral lemniscus, nucleus reticularis pontis caudalis, spinal interneuron, lower motor neuron, and muscles. Hence, five synapses, plus the neuromuscular junction, are probably involved.
\end{abstract}

The way in which neuronal systems mediate changes in behavior is the subject of an increasing number of studies. The most definitive work in this area has focused on relatively simple types of behavioral change, such as habituation and sensitization in invertebrate nervous systems such as the Aplysia (Kandel, 1978). A major advance in the analysis of these questions was elucidating the actual neural circuit that mediated the behavior

\footnotetext{
${ }^{1}$ This work was supported by National Science Foundation Grants BNS-75-01470 and BNS 78-17421, by National Institute of Mental Health Grant MH-25642, by Research Scientist Development Award MH-00004 to M. D., by Yale Medical School Summer Stipends, and by the State of Connecticut.

${ }^{2}$ To whom correspondence should be addressed at Yale University School of Medicine, the Connecticut Mental Health Center, 34 Park Street, New Haven, CT 06508.
}

being measured. Once this was done, it was possible to isolate where different types of plasticity occurred and then to determine how these changes were brought about.

In more complex vertebrate systems, comparable levels of analysis have not yet been carried out. Thus, it would be useful to find a behavior in an intact vertebrate capable of displaying several different types of plasticity that nonetheless had a neural circuit simple enough to delineate. The acoustic startle reflex may be one such behavior. Acoustic startle is being used as a model system to study habituation (Davis and Wagner, 1968; Davis, 1970), sensitization (Davis, 1972, 1974; Groves and Thompson, 1970), prepulse facilitation and inhibition (e.g., Hoffman and Ison, 1980), classical conditioning (Brown et al., 1951; Davis and Astrachan, 1978), and drug effects on behavior (cf., Davis, 1980a). In the rat, acoustic 
startle can be measured electromyographically in the hindleg with a latency of $8 \mathrm{msec}$ (Ison et al., 1973; Szabo, 1965). This extremely short latency suggests that a relatively simple circuit must be involved. This, coupled with the fact that startle displays several types of plasticity, suggests that startle may be an especially good model system for analyzing neuronal mechanisms of behavioral change in a complex organism. For this reason, the present study sought to delineate a simple neural circuit that could mediate acoustic startle.

Early work on the acoustic startle circuit can be traced to Forbes and Sherrington (1914) who observed widespread muscle reflexes to acoustic stimuli in cats that had been decerebrated at the level of the superior colliculus. Similar observations have been made in decerebrate monkeys, dogs, rabbits, and even mesencephalic humans (cf., Szabo and Hazafi, 1965). These studies indicated that auditory structures rostral to the superior colliculus (i.e., the medial geniculate and the auditory cortex) are not required for acoustic startle as one might expect given its very short latency. Decerebration at the midcollicular level also would eliminate the corticospinal tract, interstitial spinal tract, and the major part of the tectospinal tract (i.e., those fibers arising from the superior colliculus; Edwards, 1980). More recently, it has been reported that decerebrate and normal rats show similar changes in acoustic startle following administration of selected drugs or following manipulation of various stimulus parameters (Davis et al., 1977, 1980; Davis and Gendelman, 1977; Fox, 1979; Hammond, 1973).

Strass (reported in Landis and Hunt, 1939) suggested that startle is mediated by the activation of the red nucleus either directly by auditory impulses traveling through the lateral lemniscus or indirectly via impulses from the inferior or superior colliculi. From the red nucleus, impulses then could travel directly to the spinal cord via the rubrospinal tract. However, this idea was not supported by the findings of Szabo and Hazafi (1965; p. 163) that "after massive lesions at the mesencephalic level, involving the red nuclei, the entire mesencephalic reticular formation, caudally the rostral part of the pons, and rostrally the caudal portion of the diencephalon, no change could be observed in the excitability of the acoustic startle reaction." More recently, Groves et al. (1974) found also that large lesions of the mesencephalic reticular formation, which sometimes involved destruction of the red nuclei, did not abolish startle.

Another influential paper reported that the startle response, as measured by the electromyogram (EMG) ${ }^{3}$

\footnotetext{
${ }^{3}$ The abbreviations used tare: AC, aqueduct; CNIC, central nucleus of the inferior colliculus; $\mathrm{CU}$, cuneate nucleus; DCN, dorsal cochlear nucleus; DLL, dorsal nucleus of the lateral lemniscus; DP, decussation of pyramids; DR, dorsal raphe nucleus; EMG, electromyogram; ENIC, external nucleus of the inferior colliculus; HRP, horseradish peroxidase; IO, inferior olive; LL, lateral lemniscus; LM, medial lemniscus; LV, lateral vestibular nucleus; MLF, medial longitudinal fasciculus; MTB, medial nucleus of the trapezoid body; MV, medial vestibular nucleus; nVII, nucleus of the seventh nerve; P, pyramids; RGI, nucleus reticularis gigantocellularis; RPC, nucleus reticularis pontis caudalis; RPO, nucleus reticularis pontis oralis; RST, reticulospinal tract; RSTm, medial reticulospinal tract; SO, superior olive; TSV, spinal tract of the fifth nerve; VAS, ventral acoustic stria; VCN, ventral cochlear nucleus; VII, seventh nerve; VLL, ventral nucleus of the lateral lemniscus.
}

in the rat gastrocnemius muscle, occurred with a latency between 15 and 25 msec (Prosser and Hunter, 1936). On the basis of this latency, Prosser and Hunter proposed the following circuit: cochlea, eighth nerve, cochlear nucleus, inferior colliculus, reticular nucleus in midbrain, reticulospinal tract, anterior horn cells, and motor nerves to limbs.

Evidence produced by Szabo and Hazafi (1965) and Groves et al. (1976) challenged this pathway since lesions of the inferior colliculus reduced, but did not abolish, acoustic startle in rats. On the other hand, Fox (1979) recently reported that destruction of the inferior colliculus did abolish startle in rats previously given a midcollicular brain transection, when startle was defined as an EMG response in the neck muscles having an average latency of about 11 msec. Moreover, Willott et al. (1979) have argued on the basis of electrophysiological work that the inferior colliculus is probably involved in mediating an acoustic startle reflex in mice with a latency of about 17 msec.

Part of the apparent confusion in the literature regarding the exact structures necessary for acoustic startle is that different studies have measured startle reflexes that have quite different latencies. Electromyographic recordings sometimes show two and occasionally three components of the acoustic startle reflex that arrive at the muscles at slightly different times (e.g., Szabo, 1965). Studies that implicate the inferior colliculus tend to report relatively long latencies (e.g., Fox, 1979; Prosser and Hunter, 1936; Willott et al., 1979). However, as mentioned earlier, acoustic startle reflexes that have latencies of only $8 \mathrm{msec}$ in the hindleg and about $5 \mathrm{msec}$ in the neck can be measured readily in the rat (Ison et al., 1973). These extremely short latencies, coupled with the inability of lesions of the inferior colliculus to always abolish startle, suggest that an acoustic startle circuit may exist that is completely subcollicular.

In contrast to the controversy concerning the role of the inferior colliculus, there is general agreement that the reticulospinal tract originating in the pontine reticular formation is required for acoustic startle. As early as 1926, Musken (cited in Larsson, 1956) observed that animals with injuries in the midbrain reticular formation had diminished startle responses; furthermore, startle disappeared when the medial portion of the reticulum traversing the medulla and the pons was completely destroyed. Szabo and Hazafi (1965) observed that startle was abolished by lesions of the ventromedial medullopontine reticular formation at the level of the trapezoid body. However, it is not clear whether this resulted from destruction of the sensory fibers traversing the trapezoid body or from destruction of the cells that form the reticulospinal tract. 'The involvement of the latter is implicated by the findings of Hammond (1973) that relatively small lesions in the region of the nucleus reticularis pontis caudalis (RPC), that would not have damaged the ventrally located trapezoid body, markedly attenuated startle. Groves et al. (1974) also found that large lesions of the posterior regions of the reticular formation that frequently spared fibers crossing through the trapezoid body abolished startle.

A number of studies emphasize the importance of the $\mathrm{RPC}$ as being the region of the reticular formation critical 
for the mediation of acoustic startle. Lesions of this structure abolish startle (Hammond, 1973; Groves et al., 1974; Leitner et al., 1980), whereas lesions of more rostral areas of the reticular formation (Hammond, 1973; Groves et al., 1974) or more caudal areas (Hammond, 1973; Leitner et al., 1980) did not. Finally, Leitner et al. (1980) reported that lesions of the nucleus reticularis pontis caudalis abolished or attenuated both acoustic and shock-elicited startle. The fact that the lesions impaired startle elicited by different types of stimuli suggests that the lesions were effective in damaging the "motor" rather than the "sensory" limbs of these reflex arcs. Taken together, these studies support the involvement of the reticulospinal tract originating from the ventral pontine and medullary reticular formation in mediating the "motor" side of the startle circuit.

Hence, a variety of studies have implicated different auditory or motor structures in mediating the acoustic startle response. What is lacking, however, is an effective means of determining the sequence of neural structures that are involved in translating an acoustic stimulus into a muscular response. The purpose of this study was to use a combination of electrical stimulation, lesion, and anatomical tracing techniques to determine a subcollicular neural circuit that mediates the short latency startle response.

\section{Materials and Methods}

Animals. The animals were male albino Sprague-Dawley rats that weighed between 250 and $350 \mathrm{gm}$. Prior to experimentation, the rats were housed in group cages of four or five rats each and maintained on a 12-hr light, 12$\mathrm{hr}$ dark cycle. Food and water were continuously available.

Measurement of whole body startle. Five separate stabilimeter devices were used to record the amplitude of the startle response. Each stabilimeter consisted of an $8 \times 15 \times 15 \mathrm{~cm}$ Plexiglas and wire mesh cage suspended within a $25 \times 20 \times 20 \mathrm{~cm}$ steel frame. Within this frame, the cage was sandwiched between four compression springs above and a $5 \times 5 \mathrm{~cm}$ rubber cylinder below with an accelerometer (MB Electronics type 302) located between the bottom of the cage and the top of the rubber cylinder. Cage movement resulted in displacement of the accelerometer and the resultant voltage was fed through a matched accelerometer amplifier (MB Electronics model N 504), the output of which was proportional to the velocity of accelerometer displacement.

The amplified signal then was fed to a specially designed sample-and-hold circuit. Basically, this circuit consisted of five channels, one for each stabilimeter, and was used to sample the peak accelerometer voltage that occurred during a $200-\mathrm{msec}$ time band immediately after the onset of the startle-eliciting stimulus. Immediately prior to this sample period, each channel was discharged so that any spontaneous activity occurring between stimulus exposures was erased. In this way, the amplitude of the startle response of five rats was recorded simultaneously and stored in one of each of the five channels. Immediately after the sample period, the output of each of the five channels was digitized through a specially designed analog-to-digital converter and fed into a 14channel Newport printer. With two printing channels per cage, startle amplitude could vary from 0 to 99 , allowing appreciable resolution among various startle amplitudes.

The five stabilimeters were located in a $2.5 \times 2.5 \times 2$ $\mathrm{m}$, dark, ventilated, sound-attenuated chamber (Industrial Acoustic Co., IAC). They were placed $1.1 \mathrm{~m}$ from an Altec high frequency loudspeaker, which was used to provide a 90 -msec noise burst generated by a GrasonStadler noise generator, amplified through an Altec 100W power amplifier, and shaped through a Grason-Stadler electronic switch to have a rise-decay time of $5 \mathrm{msec}$. Background white noise was provided by a Grason-Stadler white noise generator. The intensity of the noise burst $(110 \mathrm{~dB})$ and the background white noise $(55 \mathrm{~dB})$ was measured with a General Radio model 1551-C sound level meter (A scale) by placing the microphone in each cage and positioning the cages to have comparable readings.

Brain stimulation. Number 00 insect pins $(0.25 \mathrm{~mm}$ in diameter) insulated to within $0.5 \mathrm{~mm}$ of the tip were lowered stereotaxically in rats anesthetized with chloral hydrate $(400 \mathrm{mg} / \mathrm{kg})$. When aiming for sites in which startle-like responses could be elicited electrically, single pulse, monophasic shocks (50 to $200 \mu \mathrm{A}, 1$ msec duration) were presented monopolarly once every 5 sec as the electrode was lowered until a point was reached in which leg movements could be elicited. This procedure was continued until a point was reached that produced the largest response (measured with an accelerometer taped to the leg) at the smallest possible current. In animals in which chronic electrical stimuli were to be used, the electrodes were cemented in place on the skull and attached to a 22 gauge wire to which "bubble clips" or jeweler's "pin clutches" could be attached. A 22 gauge wire was attached to a skull screw to serve as an indifferent electrode.

Spinal cord stimulation. Electrodes were prepared in the manner described above. To gain access to the lumbar portion of the spinal cord, the latissimus dorsi and erector spinalis muscles were dissected away from the spine in a chloral hydrate-anesthetized animal. The cord was exposed by laminectomy using rongeurs. The animal's spine was immobilized by securing clamps to the lateral processes of adjacent vertebrae. The electrode then was lowered slowly into the cord until a point was reached where low currents $(50 \mu \mathrm{A})$ elicited leg movements.

$E M G$ recordings. Rats were anesthetized with chloral hydrate and about $1 \mathrm{~cm}$ of the quadriceps femoris muscle complex was exposed. Two $17-\mathrm{cm}$ pieces of 30 gauge Teflon-coated platinum wire, bared approximately 1 to $2 \mathrm{~mm}$ at each end, were inserted into the muscle and stitched in prior to closing the skin. EMG potentials in response to startle-eliciting stimuli were recorded using a Grass 7P3 preamplifier (1- to $0.5-\mathrm{kHz}$ settings), displayed on an oscilloscope, and averaged through a FabriTex model 1072 computer. In chronic animals, the wires from the muscles were fed under the skin of the back up through an incision on the skull, crimped to Amphenol pins, and inserted into Amphenol plugs. The plug then was cemented into the skull with dental cement and secured with two or three skull screws.

Lesion study procedure. Animals were placed in the startle boxes and, 5 min later, were presented with 10 
tones at a 20 -sec intertone interval. After this pretest session, the rats were lesioned and allowed a 1-week period of postoperative recovery before retesting. Retesting used the same parameters as pretesting. After testing, the animals were sacrificed and their brains were examined histologically to determine the extent of the lesions.

Brain lesions. Electrodes were implanted using the technique described under "Brain stimulation." All lesions were anodal and $30 \mathrm{sec}$ in duration using DC current of $0.1 \mathrm{~mA}$ (anode in the brain). Lesions were placed using the following coordinates: VCN: $2.5 \mathrm{~mm}$ posterior to lambda $(\mathrm{P}), 3.4$ lateral to the midline $(\mathrm{L}), 9.2$ below the skull (D); RPC: 1.5 P, 1.5 L, 9.1 D; RGI: 3.5 P, 1.1 L, 9.0 D; RPO: 0.5 anterior to lambda (A), $1.4 \mathrm{~L}, 8.0 \mathrm{D}$; dorsal RPC: $1.5 \mathrm{P}, 1.5 \mathrm{~L}, 8.0 \mathrm{D}$; DLL: $1.0 \mathrm{~A}, 2.5 \mathrm{~L}, 6.5 \mathrm{D}$; VLL: $0.5 \mathrm{~A}, 2.3 \mathrm{~L}, 8.0 \mathrm{D}$; anterior MLF: $0.5 \mathrm{~A}, 0.1 \mathrm{~L}, 7.8 \mathrm{D}$; posterior MLF: $2.5 \mathrm{P}, 0.1 \mathrm{~L}, 8.0 \mathrm{D}$; vestibular nucleus: 3.0 $\mathrm{P}, 1.5 \mathrm{~L}, 7.5 \mathrm{D}$.

Aspiration lesions. The cerebellum was removed by aspirating the tissue through a hand-held Pasteur pipette attached to a suction pump. This was done under visual control in chloral hydrate-anesthetized rats after removing the occipital bone at the back of the skull.

Horseradish peroxidase. Animals were anesthetized with chloral hydrate and burr holes were drilled over the appropriate coordinates. Horseradish peroxidase (Sigma Chemical Co.) was iontophoresed through glass micropipettes $(75-\mu \mathrm{m}$ tips) by applying a $4.0-\mathrm{mA}$ current that alternated every $20 \mathrm{sec}$ ( $12 \mathrm{sec}$ positive, $8 \mathrm{sec}$ negative) for $20 \mathrm{~min}$. Back current was maintained during advancement and withdrawal to minimize deposit along the pipette tract. Twenty-four hours later, the rats were perfused with paraformaldehyde and glutaraldehyde in a phosphate buffer and the brains were stored in Tris buffer. Frozen sections $(50 \mu \mathrm{m})$ were cut and processed by modification (Aghajanian and Wang, 1977) of the Graham and Karnovsky method (1966) and subsequently examined with a dark-field microscope.

Histology. Upon completion of lesion and electrical stimulation experiments, the animals were sacrificed by chloral hydrate overdose and perfused intracardially with $0.9 \%$ saline followed by $10 \%$ formalin. In animals with stimulation electrodes, a small anodal current $(0.1 \mathrm{~mA}$ for $15 \mathrm{sec}$ ) was passed through the electrode to mark the tip immediately prior to sacrifice. All brains then were removed from skulls. The brains were stored for at least 1 day in $10 \%$ formalin and subsequently, $50-\mu \mathrm{m}$ frozen coronal sections were cut through the areas containing the lesions or electrode tracts. Brain sections then were mounted and stained with cresyl violet. Lesion locations were transcribed onto modified atlas sections (Palkovitz and Jacobowitz, 1974) using a Prado universal microscopic slide projector.

\section{Results}

Figure 1 shows diagrammatically the structures and pathways that may mediate the acoustic startle reflex. Figure 2 shows a composite diagram based on histology from this study as well as data from the work of others (Hammond, 1973; Leitner et al., 1980, 1981; Davis and Sheard, 1974; Szabo and Hazafi, 1965, Groves et al., 1974) indicating either lesions that abolish acoustic startle (solid areas) or those that spare startle (hatched areas).

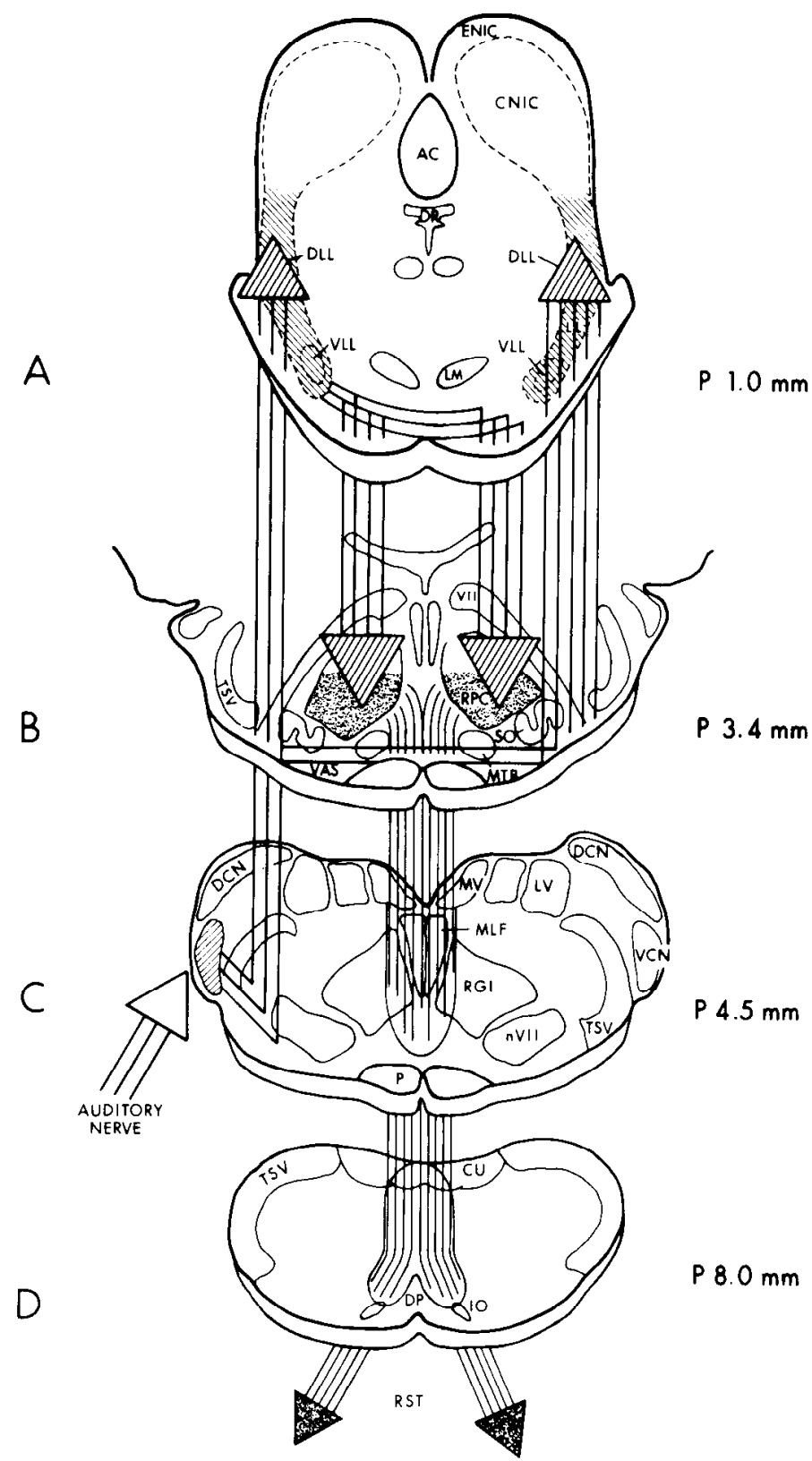

Figure 1. Schematic diagram of a primary acoustic startle circuit.

Cochlear nucleus. Acoustic neuroanatomy indicates that the cochlear nucleus would be involved in acoustic startle. To determine which regions of the cochlear nucleus are necessary, lesions were made in the ventral cochlear nucleus (VCN) and compared to lesions in structures adjacent to the VCN, including parts of the dorsal cochlear nucleus. Table I compares the mean startle amplitudes across the 10 test tones before and after lesioning. Figure 3 contains reconstructions of the histology for these animals. Ventral cochlear nucleus lesions significantly decreased startle $(t(4)=15.40 ; p<0.001$ for the change scores; $t(4)=15.93 ; p<0.001$ for the percentage of change scores). Lesions in adjacent structures, including parts of the dorsal cochlear nucleus, did not decrease startle significantly.

The latency of the acoustic startle reflex measured by the EMG in the hindlimb quadriceps muscle complex is 

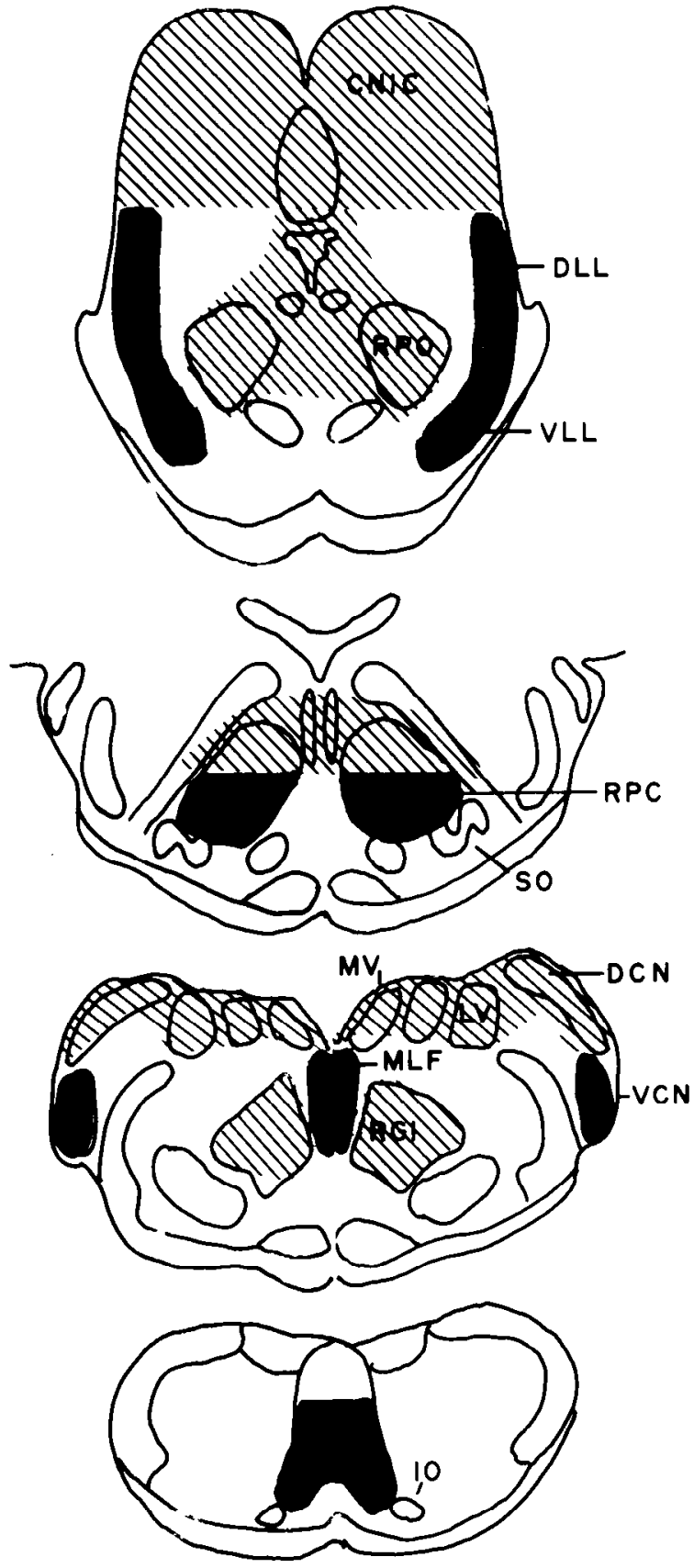

Figure 2. Lesions which abolish startle (solid areas) versus those that do not (hatched areas).

$8 \mathrm{msec}$. To determine if electrical stimulation in the VCN could produce a startle-like response of a similar latency, animals were chronically implanted with electrodes in the VCN (Fig. 4) and EMG electrodes in the quadriceps muscle complex (see "Materials and Methods"). Single pulse, monopolar stimulation (1 msec duration, 15 to 75 $\mu \mathrm{A})$ elicited a startle-like response with a latency of about $7 \mathrm{msec}$ (Fig. 5). This response looks very similar to that produced by an acoustic stimulus. "Startle" could be elicited by stimulation of the VCN only in unanesthetized or very lightly anesthetized animals. Other work has shown that "startle" elicited by bilateral stimulation through the VCN behaves like acoustic startle in paradigms that measure habituation, sensitization, prepulse inhibition, and temporal recovery (Davis, 1980b; Davis et al., 1982).

Reticular formation. Previous studies have suggested that the reticular formation is a necessary part of the acoustic startle circuit, particularly the nucleus reticularis pontis caudalis (see the introduction). To determine which region of the reticular formation is necessary for acoustic startle, lesions were placed in the nucleus reticularis pontis oralis (RPO), reticularis gigantocellularis (RGI), and dorsal or ventral regions of the reticularis pontis caudalis (RPC).

The histology of the lesions is reconstructed in Figures 6,7 , and 11 . The preoperative and postoperative startle scores are recorded in Table I. Only lesions of the ventral nucleus reticularis pontis caudalis significantly decreased startle $(t(4)=5.53 ; p<0.01$ for change scores; $t(4)=$ 23.23; $p<0.001$ for percentage of change scores). Lesions of the RPO, RGI, and dorsal RPC were ineffective in eliminating startle. To determine if these regions of the reticular formation could produce electrically elicited "startle," electrodes were placed in the RGI, RPO, and dorsal or ventral RPC. Startle-like responses could be elicited only from the ventral RPC (Fig. 8). These responses had a latency of about 5.0 msec (Fig. 5). "Startle" elicited from stimulation of the RPC could be elicited with or without chloral hydrate anesthesia with no change in EMG latency. Electrical stimulation in other regions of the reticular formation did not produce "startle" unless much higher currents were used, suggesting that such stimulation produced current spread to the ventral RPC.

TABLE I

Mean acoustic startle response prior to and following various lesions

\begin{tabular}{lcccc}
\hline \multicolumn{1}{c}{$\begin{array}{c}\text { Lesion } \\
\text { Group }\end{array}$} & Pretest & Post-test & Post - Pre & $\begin{array}{c}\text { Percent } \\
\text { Change }\end{array}$ \\
\hline VCN & 49.4 & 7.6 & $-41.8^{a}$ & $-85.0^{a}$ \\
VCN control & 42.4 & 55.6 & $13.2^{a}$ & 31.1 \\
RPC ventral & 40.0 & 8.9 & $-31.1^{b}$ & $-77.8^{a}$ \\
RPC dorsal & 45.5 & 34.7 & -10.8 & -23.7 \\
RGI & 56.2 & 38.8 & -17.4 & -25.0 \\
RPO & 51.6 & 56.1 & 4.5 & 8.7 \\
LL & 35.6 & 5.5 & $-30.1^{b}$ & $-84.6^{a}$ \\
MLF & 60.5 & 5.3 & $-55.2^{c}$ & $-91.2^{a}$ \\
MLF anterior & 62.6 & 60.3 & -2.3 & -3.7 \\
Vestibular & 49.1 & 71.8 & $22.7^{c}$ & $46.2^{c}$ \\
$\quad$ nuclei & & & & \\
\hline
\end{tabular}

${ }^{a} p<0.001$.

${ }^{b} p<0.01$.

${ }^{c} p<0.05$.

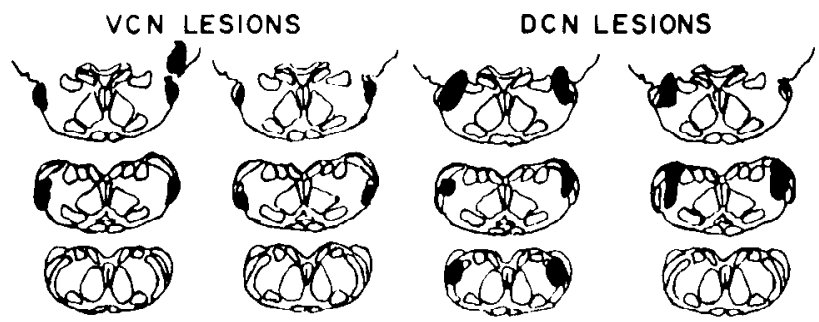

Figure 3. Histological reconstruction of the largest (left panels) or smallest (right panels) lesions (solid areas) aimed at either the ventral cochlear nucleus (VCN) or dorsal cochlear nucleus (DCN). 


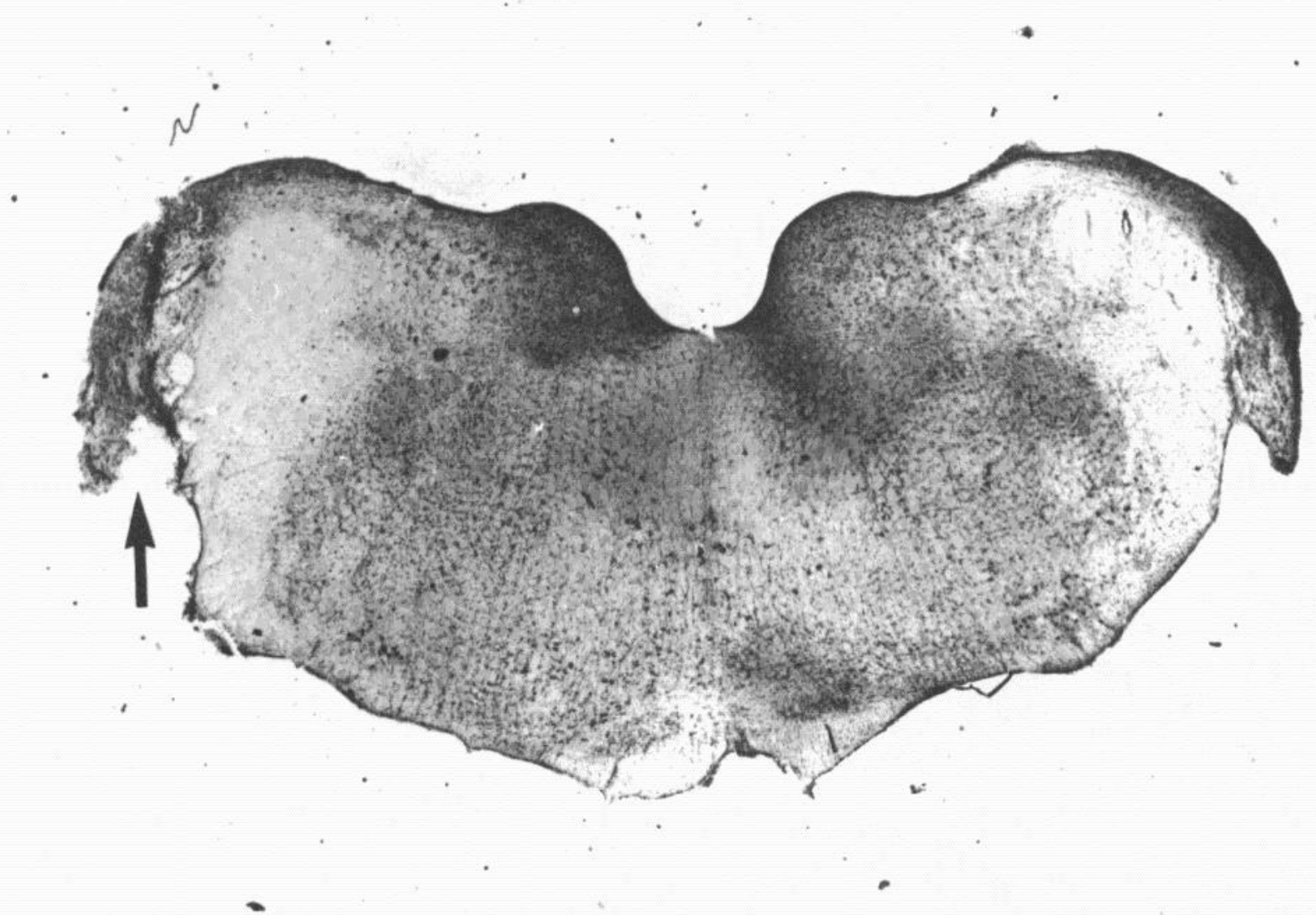

Figure 4. Photomicrograph from a brain in which electrically elicited "startle" was obtained. A small lesion produced before sacrifice marks the site (arrow) of the electrode tip in the ventral cochlear nucleus.

Horseradish peroxidase studies of the ventral RPC. These data suggested that the ventral RPC is part of an acoustic startle circuit. However, we could find no references to support a direct connection between the ventral cochlear nucleus and this region of the reticular formation. To determine if any primary auditory structures do connect to this area of the RPC, horseradish peroxidase (HRP) was microiontophoresed into the ventral RPC at a spot that produced the best electrically elicited "startle." Figure 9 shows a photomicrograph of the HRP deposit. Examination of the brains of five rats revealed that the HRP reaction product was not present in any primary auditory structures (including the inferior colliculus, superior olive, trapezoid nuclei, and cochlear nuclei) except for the nuclei of the lateral lemniscus. The contralateral dorsal nuclei had a greater concentration of reaction product compared to the contralateral ventral nuclei (Fig. 10). No reaction product was found in either of the ipsilateral nuclei of the lateral lemniscus.

Nuclei of the lateral lemniscus. The nuclei of the lateral lemniscus (dorsal and ventral) are known to receive direct input from the ventral cochlear nucleus via the ventral acoustic stria (Adams, 1979; Harrison and Irving, 1966; Warr, 1966; Fernandez and Karapas, 1967). To determine if these nuclei are necessary for startle, bilateral lesions of these nuclei were made (Fig. 11). In these animals, startle was reduced significantly after the lesions (Table I; $t(4)=4.69 ; p<0.01$ for change scores; $t(4)=20.48 ; p<0.001$ for percentage of change scores).
To determine if electrical stimulation of these structures would elicit "startle," electrodes were placed in either the dorsal or ventral nuclei of the lateral lemniscus. Single pulse stimulation (50 to $200 \mu \mathrm{A}$ ) of the dorsal nucleus (Fig. 12) elicited movement of the ipsilateral leg in both waking and chloral hydrate-anesthetized rats with a latency of about $6 \mathrm{msec}$ (Fig. 5). Stimulation of the ventral nucleus elicited a bilateral leg movement with a comparable latency.

Reticulospinal tract. To determine what descending fiber tracts might be involved in relaying startle from the brain to the spinal cord, a series of lesions was made. Previous data had shown that complete decerebration anterior to the inferior colliculus did not eliminate acoustic startle (Davis and Gendelman, 1977; Hammond, 1973; Szabo and Hazafi, 1965). This then would rule out the more anteriorly originating corticospinal, rubrospinal, interstitial spinal, and tectospinal tracts, leaving only the vestibulospinal and reticulospinal tracts. Decerebration also effectively eliminates connections from the cerebellum to the thalamus and red nucleus and hence would destroy major way stations that mediate the descending outflow of the cerebellum. Furthermore, in the present study, aspiration of the cerebellum did not abolish startle although it did attenuate it. To determine the role of the vestibulospinal and reticulospinal tracts, lesions were placed in the vestibular nuclei (origin of the vestibulospinal tracts) or the medial longitudinal fasciculus (MLF), which carries the pontine reticulospinal tract into 


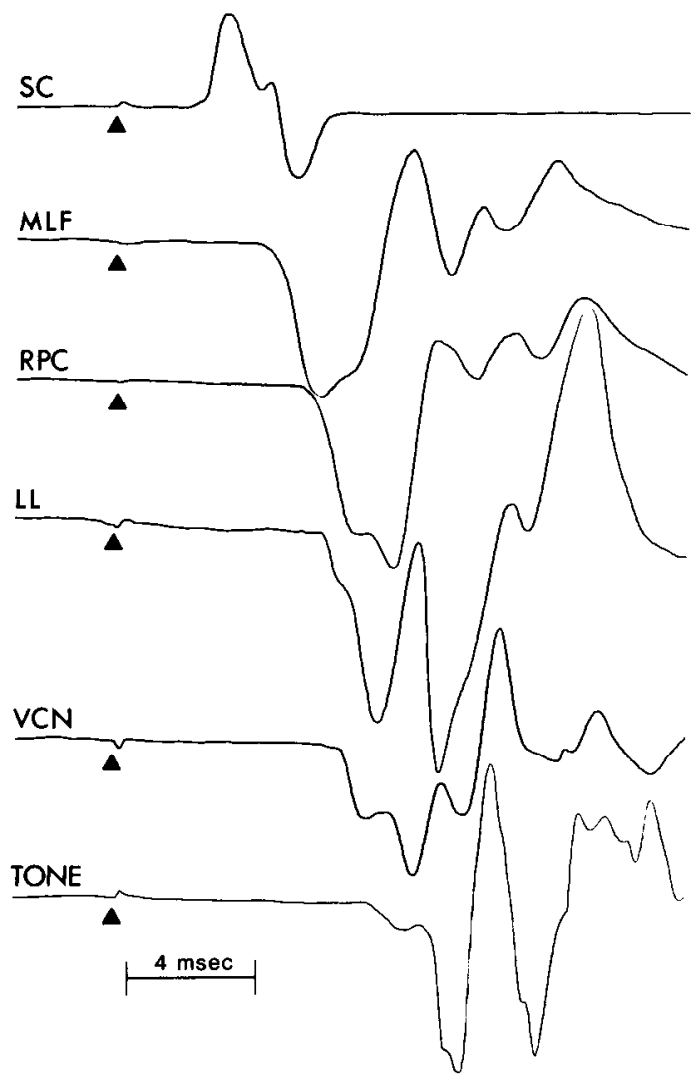

Figure 5. Electromyographic recording from the quadriceps femoris muscle complex of "startle" elicited by electrical stimulation in the spinal cord (SC), medial longitudinal fasciculus (MLF), nucleus reticularis pontis caudalis (RPC), nuclei of the lateral lemniscus (LL), or ventral cochlear nucleus (VCN) or by a tone.

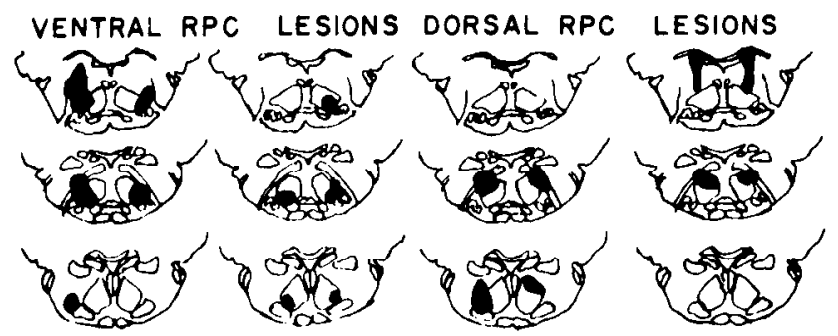

Figure 6. Histological reconstruction of the largest (left panels) and smallest (right panels) lesions (solid areas) aimed at the ventral or dorsal regions of the nucleus reticularis pontis caudalis (RPC). the cord. The histology is shown in Figures 7 and 11. Table I indicates that lesions of the vestibular nuclei not only did not decrease startle but slightly increased it, even though these animals demonstrated marked motor impairment, particularly in their ability to right themselves. In contrast, lesions of the MLF (Fig. 7) eliminated startle if they were placed caudal to the anterior limit of the nucleus of the seventh cranial nerve $(t(4)=3.53 ; p$ $<0.05$ for change scores; $t(4)=20.53 ; p<0.001$ for percentage of change scores). More anteriorly placed lesions within the MLF (Fig. 11) did not alter startle, suggesting that components of the MLF which enter more anterior than the RPC are not essential for startle.

To determine if electrical stimulation of the MLF would elicit "startle," electrodes were placed in the anterior and posterior MLF regions. Only posterior MLF regions (Fig. 13) were capable of producing an electrically elicited "startle" response which had a latency of about 4.5 msec (Fig. 5). The latency was unchanged by the presence or absence of chloral hydrate anesthesia.

The hindlimb response of acoustic startle must be mediated by motor neurons originating in the lumbar region of the cord. To determine if a startle-like response could be elicited from the lumbar spinal cord, an electrode was lowered into the cord. Stimulation $(50 \mu \mathrm{A})$ elicited leg movements with an EMG latency of $2.5 \mathrm{msec}$ in lightly or deeply anesthetized rats (Fig. 5).

\section{Discussion}

The present series of experiments provides evidence that a neural circuit that mediates an acoustic startle reflex with an 8-msec latency in the hindlegs consists of the ventral cochlear nucleus, the nuclei of the lateral lemniscus, a ventral region of the nucleus reticularis pontis caudalis, and the spinal cord. Thus, four or perhaps five central synapses are required (depending upon whether interneurons in the spinal cord are involved).

Ventral cochlear nucleus. Bilateral lesions of the posterior ventral cochlear nucleus abolished acoustic startle. In waking rats, bilateral electrical stimulation of this region elicited startle-like responses with a latency of about 7.0 to $7.5 \mathrm{msec}$. In contrast, lesions that destroyed most of the dorsal cochlear nucleus or other areas adjacent to, but not including, the VCN failed to abolish startle.

Anatomical studies indicate that cells in the VCN receive direct projections from auditory neurons and hence could serve as the first central synapse in mediat-
RGI LESIONS
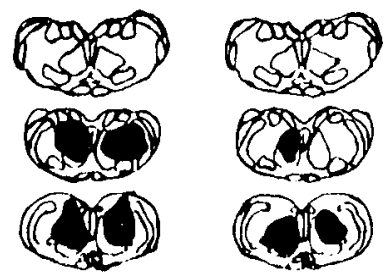

-

Figure 7. Histological reconstruction of the largest (left panels) and smallest (right panels) lesions (solid areas) of the nucleus reticularis gigantocellularis (RGI), the medial longitudinal fasciculus (MLF), or the medial and lateral vestibular nuclei.

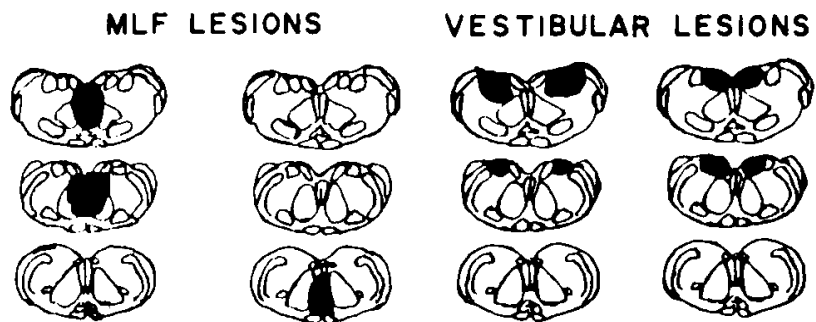

MLF LESIONS

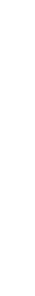




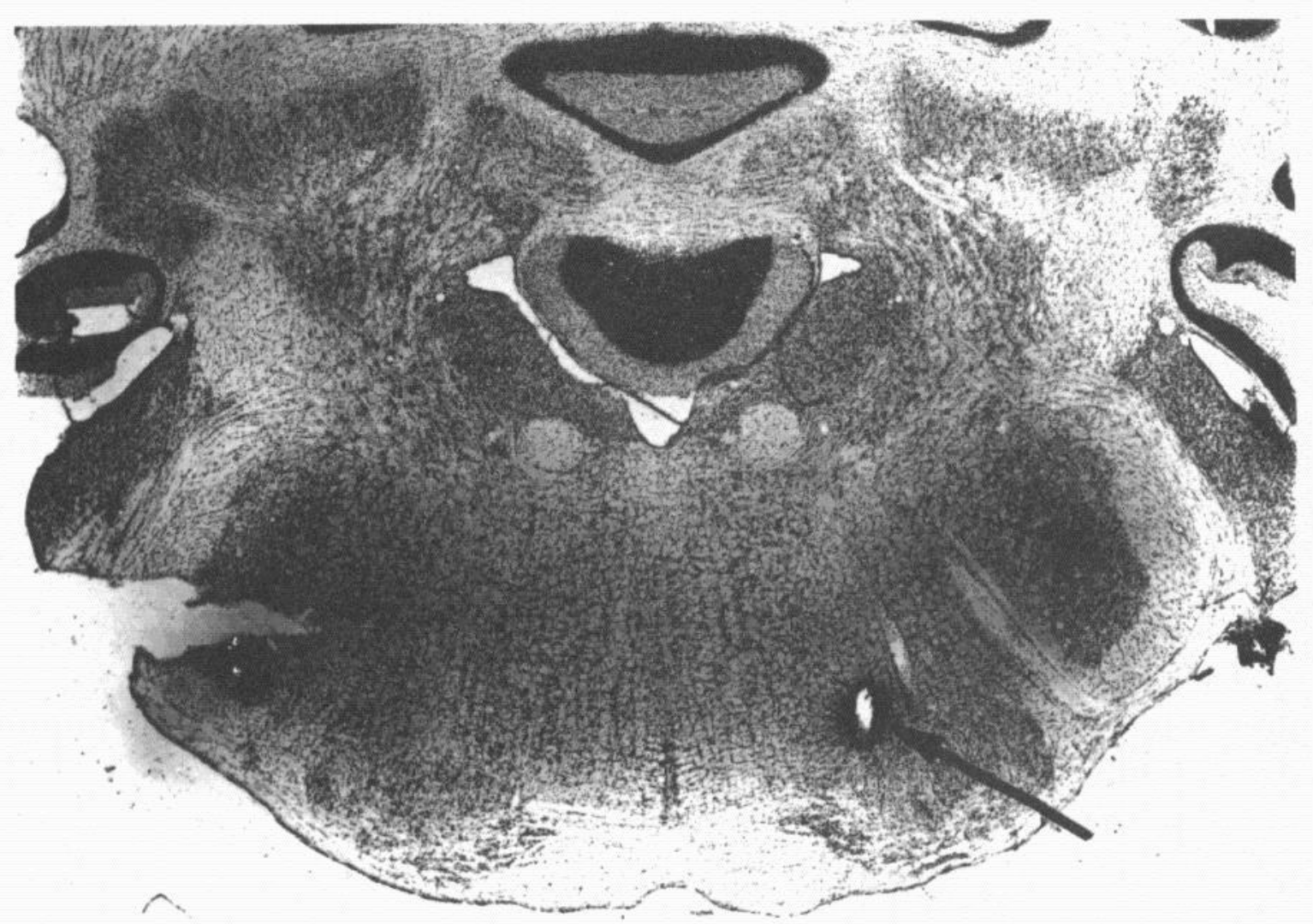

Figure 8. Photomicrograph from a brain in which electrically elicited "startle" was obtained. A small lesion produced before sacrifice marks the site (arrow) of the electrode placement in the ventral nucleus reticularis pontis caudalis (RPC).

ing acoustic startle. Single unit studies indicate that cells in the VCN fire to stimulus onset (the effective part of an auditory stimulus used to elicit startle) with very short latencies (Britt and Starr, 1976; Godfrey et al., 1975; Pfeiffer, 1966). In contrast, cells in the dorsal cochlear nucleus typically have longer latencies, making them less likely to mediate the short latency reflex studied herein.

It is unclear in this study whether the VCN efferents which mediate acoustic startle travel ipsilaterally, contralaterally, or bilaterally. Anatomical studies indicate that most fibers from the cochlear nucleus cross the midline via the ventral acoustic stria through the trapezoid body before ascending to higher structures. However, some fibers do ascend ipsilaterally. Cannon (1977) has shown that small knife cuts that damage only the ventral acoustic stria and spare ipsilateral fibers abolish startle. This effect seemed dependent on the severing of only the most ventral fibers, since dorsal structures were spared by making the knife cuts using a ventral approach. This work suggests that the fibers essential to acoustic startle travel contralaterally. However, it should be noted that such lesions may be eliminating startle by destroying the motor portion of the startle pathway, specifically the reticulospinal axons as they descend in the MLF.

Dorsal and lateral nuclei of the lateral lemniscus. Earlier as well as more recent work implicated the inferior colliculus as a critical part of the acoustic startle reflex. Our data indicate, however, that the dorsal and ventral nuclei of the lateral lemniscus may be necessary and sufficient for mediating the 8-msec startle reflex described herein. Lesions of these structures abolished acoustic startle. Electrical stimulation of these nuclei at low currents elicited startle-like responses with a latency of about $6 \mathrm{msec}$. Finally, these nuclei were heavily labeled after HRP was applied to areas in the RPC critical for startle. Cells in the nuclei of the lateral lemniscus are known to receive direct projections from the VCN (Adams, 1979; Harrison and Irving, 1966; Fernandez and Karapas, 1967) and respond to the onset of loud clicks with a latency of 2 to $3 \mathrm{msec}$ (M. Davis, unpublished observations), consistent with the $6 \mathrm{msec}$ reported above for EMG responses produced by electrical stimulation of the LL. In contrast, neither the dorsal external nor the central nucleus of the inferior colliculus fulfilled all of these criteria.

It is possible, however, that ventral and caudal aspects of the external nucleus of the inferior colliculus might be involved, since this area would be very close to the dorsal nucleus of the lateral lemniscus. In cats, Conlee (1979) has shown that injection of radioactive leucine at the border between the inferior colliculus and the DLL results in labeling in a variety of auditory areas as well as in rostral and ventral regions of the ipsilateral nucleus reticularis paragigantocellularis lateralis. In the rat, this latter area corresponds to the border between RPC and RGI, an area which appears to be critical for startle. Interestingly, Conlee (1979; p. 344) states that "more dorsal CNIC injections led to a visibly less dense distribution of grains over this region of the reticular-formation, which suggests that the efferent reticular connection 


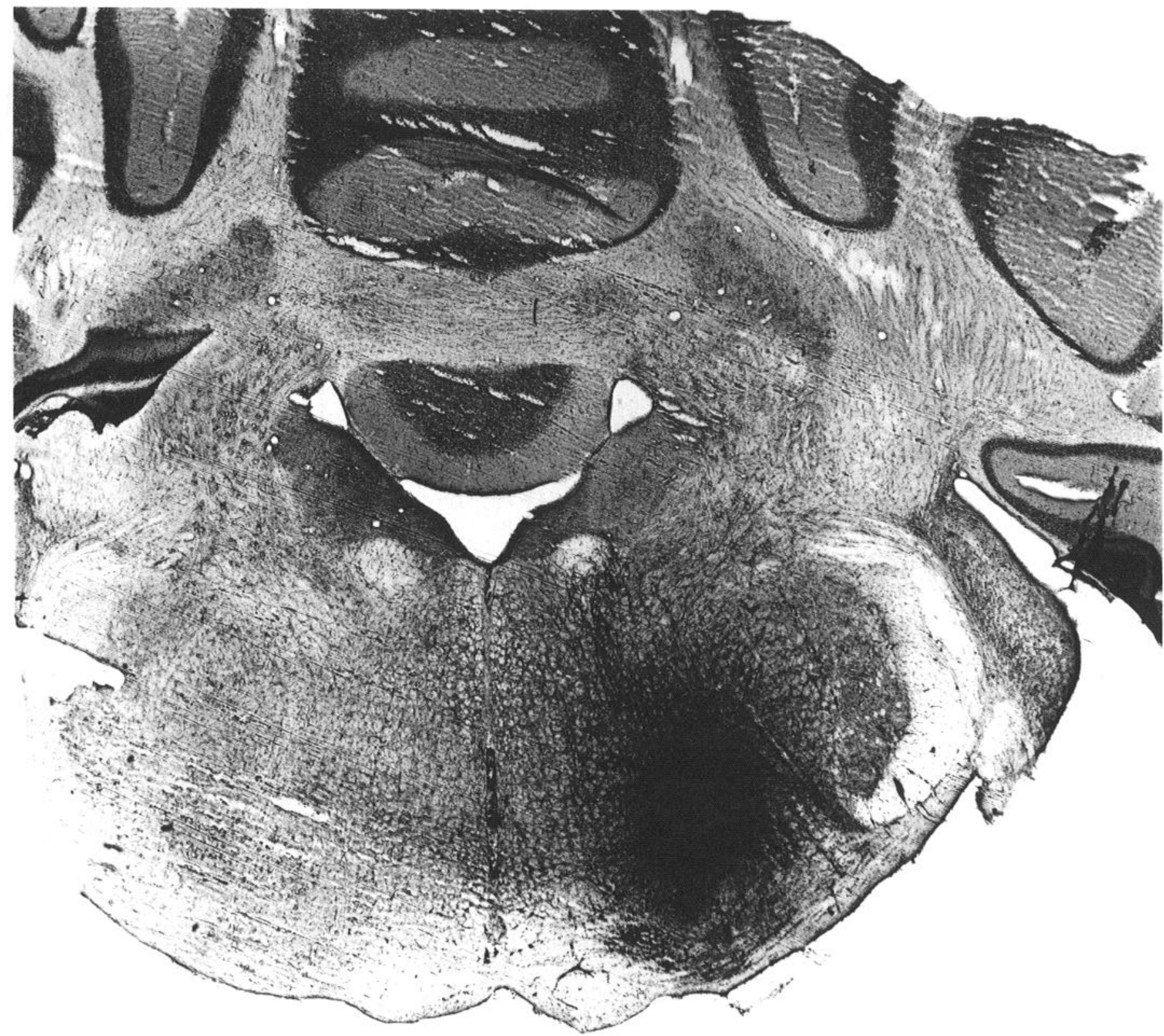

Figure 9. Deposit of horseradish peroxidase within the ventral nucleus reticularis pontis caudalis.

largely arises from the more ventrolateral IC and/or DNLL." More recently Kudo (1981) has shown in cats that radioactive leucine infused into either the DLL or VLL results in terminal labeling just dorsal to the trapezoid body and superior olive. This is the area of the RPC where lesions abolish acoustic startle and electrical stimulation elicits startle-like responses.

A major obstacle in delineating an entire acoustic startle circuit was that very little data were available concerning pathways from auditory areas to the reticular formation and spinal cord with sufficiently short conduction times to mediate the 8-msec latency response studied here. The known connections between the inferior colliculus and the lateral pontine nucleus (Kawamura, 1975) did not seem to be involved, since lesions of the inferior colliculus did not abolish acoustically elicited startle and electrical stimulation of the inferior colliculus did not produce startle-like responses. Connections between the nucleus of the trapezoid body and the reticular formation (Warr, 1966, 1969) did not seem sufficient since anterior lesions in the nuclei of the lateral lemniscus, which would spare the trapezoid body, abolished startle.

To determine the possible connections, horseradish peroxidase (HRP) was iontophoresed into specific ventral regions of the nucleus reticularis pontis caudalis which parallel studies indicated were critical for acoustic startle. Known auditory areas then were examined for reaction product. Heavy deposits were found in the ventral and particularly dorsal contralateral nuclei of the lateral lemniscus, suggesting a direct neuronal projection from a known auditory structure to this critical region of the nucleus reticularis pontis caudalis. In contrast, no 


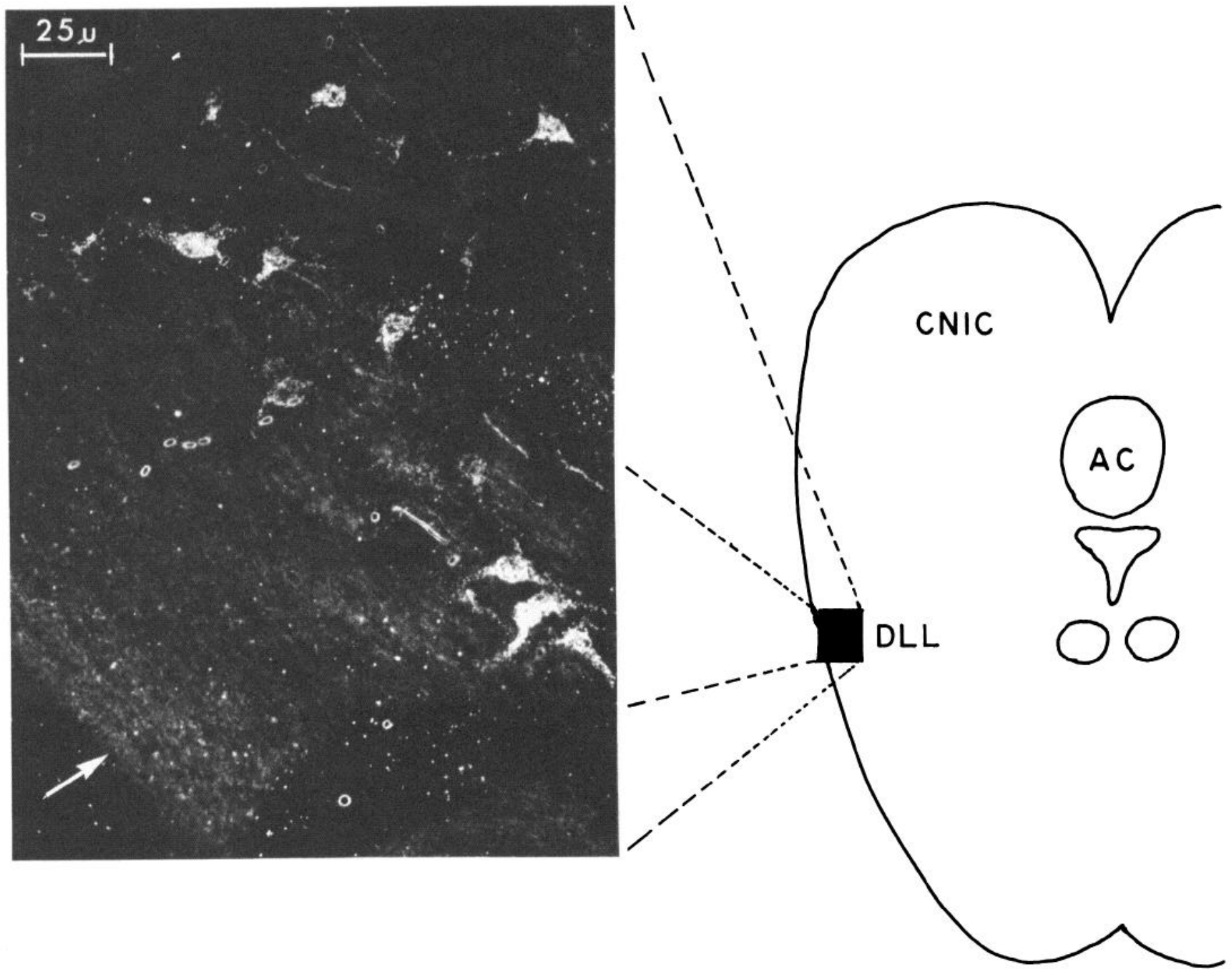

Figure 10. Photograph of cells labeled with horseradish peroxidase in the dorsal nucleus of the lateral lemniscus (DLL) after a deposit was placed in the ventral nucleus reticularis pontis caudalis. The arrow marks the lateral edge of the brain slice.

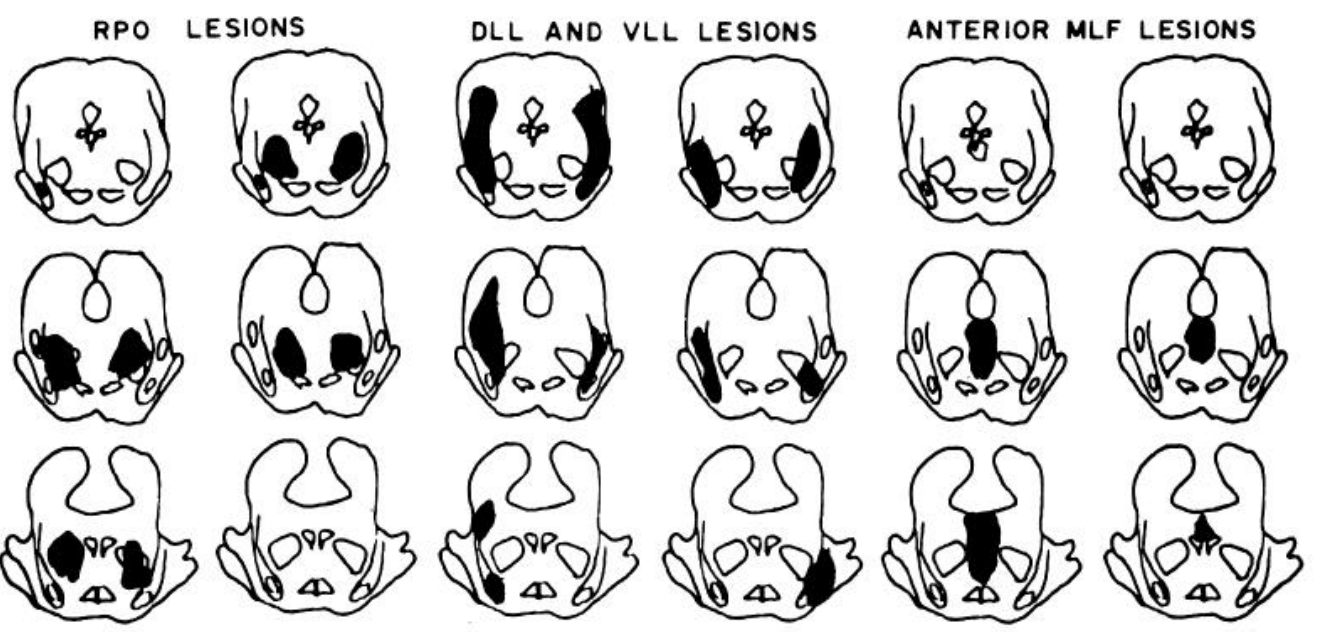

Figure 11. Histological reconstruction of the largest (left panels) and smallest (right panels) lesions (solid areas) of the nucleus reticularis pontis oralis (RPO), the dorsal and ventral nuclei of the lateral lemniscus (DLL and VLL), or anterior levels of the medial longitudinal fasciculus (MLF). 


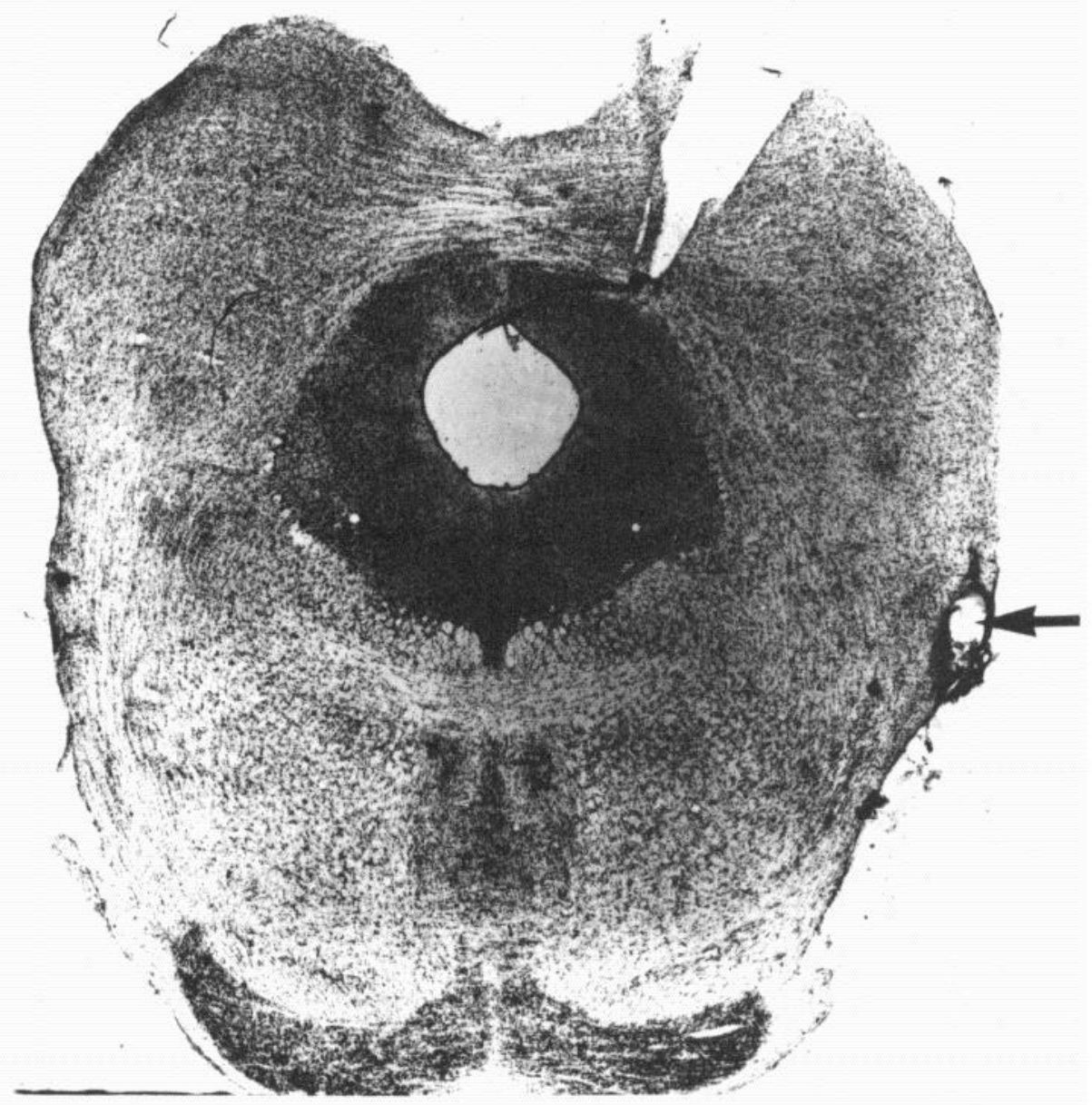

Figure 12. Photomicrograph from a brain in which electrically elicited "startle" was obtained. A small lesion produced before sacrifice marks the site (arrow) of electrode placement in the dorsal nucleus of the lateral lemniscus (DLL). (This region is called vrll in the atlas of Konig and Klippel, 1963.)

consistent labeling was found in other auditory areas, such as the cochlear nuclei, superior olives, trapezoid bodies, or inferior colliculi.

Furthermore, Gallager and Pert (1978) did not report reaction product in the DLL, VLL, or any other auditory structures when injections of HRP were made in the dorsal regions of the RPC, areas which do not support electrically elicited "startle" and do not abolish acoustic startle when lesioned. These data suggest a specific projection from the nuclei of the lateral lemniscus to the ventral RPC, the area postulated to be necessary for acoustic startle.

Nucleus reticularis pontis caudalis. Lesions of a ventral region at the border between the nucleus reticularis pontis caudalis and the nucleus reticularis gigantocellularis abolished or markedly attenuated acoustic startle. Electrical stimulation in this region produced startle-like responses with a latency of about $5 \mathrm{msec}$. As mentioned previously, reaction product from horseradish peroxidase iontophoresed into this area was found in the nuclei of the lateral lemniscus, indicating a direct auditory projection to this part of the reticular formation. In contrast, lesions of more rostral, caudal, or dorsal areas in the reticular formation did not abolish startle, and electrical stimulation of these areas did not elicit "startle." These data confirm and extend earlier lesion work pointing to this part of the pontomedullary reticular formation as being critical for startle (Groves et al., 1974; Hammond, 1973; Leitner et al., 1980; Szabo and Hazafi, 1965).

Anatomical and electrophysiological studies in cats indicate that this region of the reticular formation would be a likely area to mediate the very fast startle reflex investigated in the present study. Very short latency unit responses can be measured in cells in this area following acoustic stimulation (Remmel et al., 1980). Studies in which horseradish peroxidase was placed at various levels of the spinal cord in the cat indicated that cells in this area project to all levels of the spinal cord (Kuypers and Maisky, 1975; Tohyama et al., 1979). These neurons have been shown to have direct, monosynaptic connections with motor neurons in the spinal cord (Grillner and Lund, 1968; Grillner et al., 1971; Peterson, 1979; Peterson et al., 1979; Wilson and Yoshida, 1969; Wilson et al., 1970) which would allow the most rapid transmission from the reticular formation out to the muscles. The full acoustic startle reflex is a complex but coordinated behavior consisting of a rapid sequence of muscle contractions that begin in the neck and back and extend down to the foreand hindpaws. It is noteworthy, therefore, that the majority of the neurons in the pontomedullary reticular 


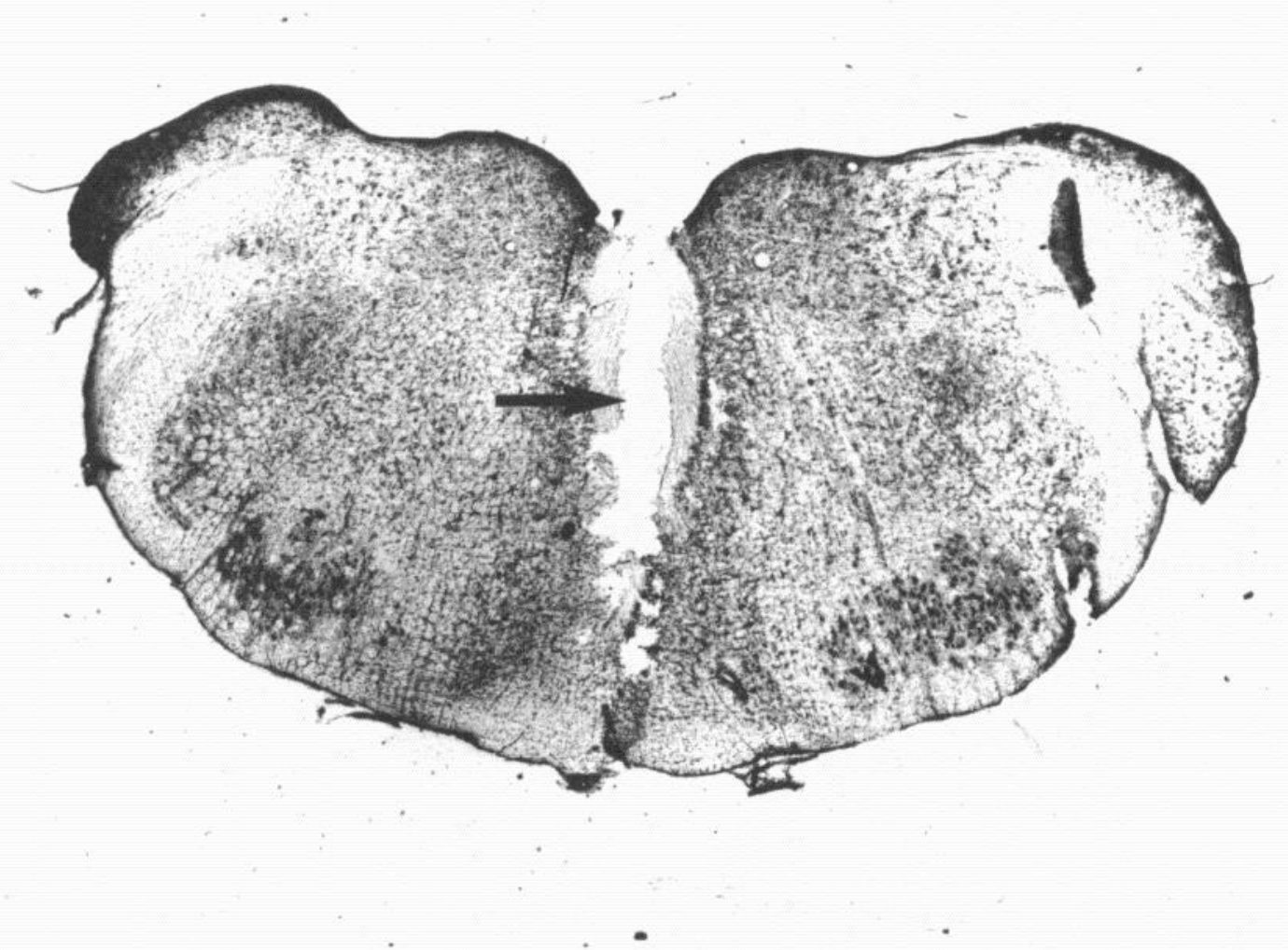

Figure 13. Photomicrograph from a brain in which electrically elicited "startle" was obtained. A lesion produced before sacrifice marks the site (arrow) of electrode placement in the medial longitudinal fasciculus (MLF).

formation that project to the cervical spinal cord also send branches to lower spinal levels, including the lumbar cord. Such a system would be well suited for a rapid sequential activation of muscle groups throughout the spinal axis.

Axons from cell bodies in this area of the reticular formation project down the spinal cord through the medial reticulospinal tract (RSTm). This tract runs in or close to the medial longitudinal fasciculus in the medulla and then in the ventromedial funiculus in the spinal cord. On the other hand, cell bodies in the RGI project to the cord through the ipsilateral and contralateral reticulospinal tracts (Peterson et al., 1975). The RSTm is well suited for mediating a short latency acoustic startle reflex since it terminates in the ventral horn, permitting direct monosynaptic connections with lower motor neurons (Grillner et al., 1971; Peterson et al., 1979) in contrast to the ipsilateral and contralateral tracts that project to the dorsal horn. In addition, the mean conduction velocity within the RSTm is about $100 \mathrm{~m} / \mathrm{sec}$ compared to about $70 \mathrm{~m} / \mathrm{sec}$ for the other tracts. Finally, Peterson (1979) noted that $71 \%$ of the RSTm neurons project as far as the lumbar cord, whereas only $63 \%$ of the ipsilateral and $51 \%$ of the contralateral tracts project all of the way down to the lumbar cord.

In the present study, electrical stimulation on the midline in the MLF elicited startle-like responses with a latency of about $4.5 \mathrm{msec}$. At a level beginning just posterior to the motor nucleus of the seventh cranial nerve, lesions of the MLF abolished or attenuated startle.
More anterior lesions of the MLF did not eliminate startle, suggesting that components of the MLF which enter rostral to the RPC are not essential to the acoustic startle reflex. In contrast, electrical stimulation more laterally in the RGI at the same anterior-posterior level did not elicit "startle" responses at reasonable currents. Consistent with this, Peterson et al. (1979) found that stimulation at comparable points of the RGI in the cat failed to activate lower motor neurons in the spinal cord but instead tended to produce inhibitory effects based on intracellular criteria.

At the present time, it is not clear whether interneurons in the spinal cord are involved in the primary acoustic startle circuit. As stated above, the RSTm contains axons that make monosynaptic connections onto lower motor neurons although these probably represent the minority of connections. The convergent data outlined above implicating the RSTm in startle would suggest, therefore, that interneurons would not be involved. On the contrary, other data suggest that interneurons might be involved. Peterson et al. (1979) noted that activation of lower motoneurons followed stimulation in the reticular formation at rates as high as 10 pulses/sec, whereas polysynaptic pathways did not follow such high rates. In both anesthetized and waking rats, we find that startle-like responses decline precipitously when stimulation in the MLF exceeds rates of about 1 pulse/sec. This decline does not seem to be attributable to the neuromuscular junction, since direct stimulation within the spinal cord at rates up to 10 to $20 / \mathrm{sec}$ does not 
decrease and may even increase responses measured in the same muscle. These observations suggest that an interneuron may be involved in relaying information from the RST to the lower motor neuron. In addition, the 2-msec difference in latency between startle elicited from the MLF versus the spinal cord seems to he slightly too long to be attributed entirely to conduction velocity down the cord (assuming conduction velocities of 70 to $100 \mathrm{~m} / \mathrm{sec}$ ), again suggesting the involvement of interneurons.

Alternative pathways. It should be noted that other startle circuits could exist that mediate both short and longer latency responses. Thus, it is possible that the superior olive provides an important link between the ventral cochlear nucleus and the DLL. In the cat, most of the inputs to the DLL come from the superior olive rather than the cochlear nucleus (Glendenning et al., 1981). Thus far, our techniques have not been selective enough to evaluate the role of the superior olive. Lesions of the superior olives do attenuate startle markedly, but it is not clear whether this is due to destruction of the olives per se or to fibers of passage or cells in the nearby RPC. Microstimulation techniques or single unit recording techniques may have to be used to settle this issue. Furthermore, it is possible that an even simpler circuit could exist consisting of the VCN and VLL which then would project directly down the spinal cord. In the cat, the VLL receives heavy input from the VCN compared to only sparse projections from the superior olive (Glendenning et al., 1981). Preliminary data from our laboratory indicate that reaction product can be found in an area just medial to the VLL after large HRP deposits in the spinal cord. Similar projections have been observed in the opossum and have been suggested to be involved in mediating short latency acoustic reflexes (Martin et al., 1979). These "paralemniscal zones" are all the more interesting since they project heavily to the facial motor nucleus (Henkel and Edwards, 1978), providing a possible pathway for mediating facial components of the startle reflex. The abolishment of startle after lesions in the RPC might have occurred, therefore, by destruction of fibers of passage emanating from the area medial to the VLL. To test this, kainic acid lesions of the ventral RPC could be used to see if selective destruction of cell bodies would occur and if this would spare startle.

Other sets of pathways are probably required to explain the longer latency startle reflexes reported by others. Horlington (1968) has shown that a range of startle latencies can be recorded by accelerometers when a large number of rats are tested. Szabo (1965) and Prosser and Hunter (1936) have reported latencies as long as 15 to 25 msec and Fox (1979) has recorded EMGs from the neck with latencies of $11 \mathrm{msec}$ which disappear after lesioning of the inferior colliculus. Willott et al. (1979) have recorded latencies of 10 to $12 \mathrm{msec}$ from cells responsive to acoustic stimuli in the inferior colliculus; these cells demonstrate some of the characteristics of the acoustic startle reflex, such as sensitivity to rise-decay time and interstimulus interval. Hence, a longer latency pathway involving transmission throughout the inferior colliculus may exist also. It should be emphasized, however, that each of the lesions that abolished startle defined by an 8- msec latency also abolished whole body startle measured in the accelerometer. Thus, there was no indication that these lesions abolished a short latency response but spared a longer latency one.

Finally, it should be acknowledged that the data are still unclear with regard to the degree of crossing within the proposed startle pathway. Electrical stimulation of the DLL elicits purely ipsilateral leg movements. This would be consistent with the observations of Conlee (1979) and Kudo (1981) in cats that radioactive leucine placed near the DLL reveals an ipsilateral projection to caudal levels of the RPC near the superior olive, an area where electrical stimulation also produces ipsilateral leg movements. However, we did not find labeled cells in the ipsilateral DLL after HRP deposits in the RPC but only contralateral deposits at a point slightly more ventral where electrical stimulation elicited bilateral leg movements. It is possible, therefore, that the ipsilateral projections from the DLL would have been found with deposits of HRP in more caudal regions of the $\mathrm{RPC}$, but we have not yet been able to demonstrate this. On the other hand, Griffith et al. (1980) reported that injection of radioactive leucine into the VLL of the rat did not label cells in the ventral RPC but only axons that passed through this region on route to the contralateral cochlear nucleus. However, these deposits were somewhat more ventral than the spot where we find labeled cells after HRP. Clearly, more systematic studies in the rat using combined anterograde and retrograde tracing techniques at points critical for startle will have to be done to determine where various pathways cross and how they ultimately project down the spinal cord.

As outlined earlier, startle has proven to be an excellent model system with which to study phenomena such as habituation, sensitization, prepulse inhibition, and classical conditioning. It has also proven to be an extremely sensitive behavior for studying a variety of drugs. The delineation of a neural circuit that mediates startle now provides a foundation for determining where different types of behavioral or pharmacological plasticity occur or where they are expressed to alter behavior. One could begin to explore these questions by eliciting "startle" at different points along this circuit before and after different treatments. For example, if a certain drug acted by increasing transmission in the lateral lemniscus, this drug should increase "startle" elicited in the cochlear nucleus, since stimulation here eventually would traverse the part of the circuit where the drug acted. However, the drug should not affect "startle" elicited by electrical stimulation through the nucleus reticularis pontis caudalis, since this would go directly to the lower part of the circuit and hence bypass the place where the drug acted. Differential as well as similar effects of selected drugs on "startle" elicited electrically from different points in this circuit have, in fact, been found (Commissaris and Davis, 1982). Similarly, it should also be possible to record single unit activity at various points along the circuit during the course of repetitive elicitation of startle before and after different treatments. Hence, the drug should increase unit activity in areas beyond, but not before, the lateral lemniscus. By combining these techniques of electrical elicitation of "starlle" and single unit recording along 
points of the neuronal startle circuit, it should be possible to determine more fully how the brain mediates behavioral changes.

\section{References}

Adams, J. C. (1979) Ascending projections to the inferior colliculus. J. Comp. Neurol. 183: 519-538.

Aghajanian, G. K., and R. Y. Wang (1977) Habenular and other midbrain raphe afferents demonstrated by a modified retrograde tracing technique. Brain Res. 122: 229-242.

Britt, R., and A. Starr (1976) Synaptic events and discharge patterns of cochlear nucleus cells. I. Steady-frequency tone bursts. J. Neurophysiol. 39: 162-178.

Brown, J. S., H. I. Kalish, and I. E. Farber (1951) Conditioned fear as revealed by magnitude of startle response to an auditory stimulus. J. Exp. Psychol. 41: 317-327.

Cannon, J. T. (1977) Behavioral and neuroanatomical analyses of the pinna reflex, acoustic startle reflex and escape from intense noise in the rat. An unpublished thesis at the graduate school of the University of Maine at Orono.

Commissaris, R. L., and M. Davis (1982) Opposite effects of $N, N$-dimethyltryptamine (DMT) and 5-methoxy- $N, N$-dimethyltryptamine (5-MeODMT) on acoustic startle: Spinal vs. brain sites of action. Neurosci. Biobehav. Rev., in press.

Conlec, J. W. (1979) Descending auditory projections from the inferior colliculus and nuclei of the lateral lemniscus in the cat. An unpublished thesis at the graduate school of the University of Chicago.

Davis, M. (1970) Effects of interstimulus interval length and variability on startle response habituation in the rat. J. Comp. Physiol. Psychol. 72: 177-192.

Davis, M. (1972) Differential retention of sensitization and habituation of the startle response in the rat. J. Comp. Physiol. Psychol. 78: 260-267.

Davis, M. (1974) Sensitization of the rat startle response by noise. J. Comp. Physiol. Psychol. 87: 571-581.

Davis, M. (1980a) Neurochemical modulation of sensory-motor reactivity: Acoustic and tactile startle reflexes. Neurosci. Biobehav. Rev. 4: 241-263.

Davis, M. (1980b) Habituation and sensitization of a startle-like response elicited by electrical stimulation at different points in the acoustic startle circuit. In Advances in Physiological Science. Vol. 16: Sensory Functions, E. Grastyan and P. Molnar, eds., pp. 67-78, Pergamon Press, Elmsford, NY.

Davis, M., and D. I. Astrachan (1978) Conditioned fear and startle magnitude: Effects of different footshock or backshock intensities used in training. J. Exp. Psychol. (Anim. Behav.) 4: 95-103.

Davis, M., and P. M. Gendelman (1977) Plasticity of the acoustic startle reflex in acutely decerebrate rats. J. Comp. Physiol. Psychol. 91: 549-563.

Davis, M., and M. H. Sheard (1974) Habituation and sensitization of the rat startle response: Effects of raphe lesions. Physiol. Behav. 12: 425-431.

Davis, M., and A. R. Wagner (1968) Startle responsiveness following habituation to different intensities of tone. Psychon. Sci. 12: 337-338.

Davis, M., J. M. Cederbaum, G. K. Aghajanian, and D. S. Gendelman (1977) Effects of clonidine on habituation and sensitization of acoustic startle in normal, decerebrate and locus coeruleus lesioned rats. Psychopharmacology (Berlin) 51: $243-253$.

Davis, M., D. I. Astrachan, P. M. Gendelman, and D. S. Gendelman (1980) 5-Methoxy- $N, N$-dimethyltryptamine: Spinal cord and brainstem mediation of excitatory effects on acoustic startle. Psychopharmacology (Berlin) 70: 123-130.

Davis, M., T. Parisi, D. S. Gendelman, M. D. Tischler, and J.
H. Kehne (1982) Habituation and sensitization or electrically elicited "startle" reflexes. Science, in press.

Edwards, S. B. (1980) The deep cell layers of the superior colliculus: Their reticular characteristics and structural organization. In The Reticular Formation Revisited, J. A. Hobson and M. A. B. Brazier, eds., pp. 193-209, Raven Press, New York.

Fernandez, C., and F. Karapas (1967) The course and termination of the striae of Monoakow and Held in the cat. J. Comp. Neurol. 131: 371-386.

Forbes, A., and C. S. Sherrington (1914) Acoustic reflexes in the decerebrate cat. Am. J. Physiol. 35: 367-376.

Fox, J. E. (1979) Habituation and prestimulus inhibition of the auditory startle reflex in decerebrate rats. Physiol. Behav. 23: 291-297.

Gallager, D. W., and A. Pert (1978) Afferents to brain stem nuclei (brain stem raphe, nucleus reticulari pontis caudalis and nucleus gigantocellularis) in the rat as demonstrated by microiontophoretically applied horseradish peroxidase. Brain Res. 144: 257-275.

Glendenning, K. K., J. K. Brunso-Bechtold, G. C. Thompson, and R. B. Masterton (1981) Ascending auditory afferents to the nuclei of the lateral lemniscus. J. Comp. Neurol. 197: 673-703.

Godfrey, D. A., N. Y. S. Kiang, and B. E. Norris (1975) Single unit activity in the dorsal cochlear nucleus of the cat. J. Comp. Neurol. 162: 269-284.

Graham, R. C., Jr., and J. J. Karnovsky (1966) The early steps or absorption of injected HRP in the proximal tubules of mouse kidney: Ultrastructural cytochemistry by a new technique. J. Histochem. Cytochem. 4: 291-302.

Griffith, D. L., M. H. Cooper, and L. G. Massopost (1980) Efferent projections of the ventral nucleus of the lateral lemniscus. Soc. Neurosci. Abstr. 6: 556.

Grillner, S., and S. Lund (1968) The origin of a descending pathway with monosynaptic action on flexor motoneurons. Acta Physiol. Scand. 74: 274-284.

Grillner, S., T. Hongo, and S. Lund (1971) Convergent effects on alpha motoneurons from the vestibulospinal tract and a pathway descending in the medial longitudinal fasciculus. Exp. Brain Res. 12: 457-479.

Groves, P. M., C. J. Wilson, and R. D. Boyle (1974) Brain stem pathways, cortical modulation and habituation of the acoustic startle response. Behav. Biol. 10: 391-418.

Groves, P. M., C. J. Wilson, and S. W. Miller (1976) Habituation of the acoustic startle response: A neuronal systems analysis of habituation in the intact animal. Adv. Psychobiol. 3: 327-379.

Hammond, G. R. (1973) Lesions of pontine and medullary reticular formation and prestimulus inhibition of the acoustic startle reaction in rats. Physiol. Behav. 10: 239-243.

Harrison, J. M., and R. Irving (1966) Ascending connections of the anterior ventral cochlear nucleus in the cat. J. Comp. Neurol. 126: 51-64.

Henkel, C. K., and S. B. Edwards (1978) The superior colliculus control of pinna movements in the cat: Possible anatomical connections. J. Comp. Neurol. 182: 763-776.

Hoffman, H. S., and J. R. Ison (1980) Reflex modification in the domain of startle. I. Some empirical findings and their implications for how the nervous system processes sensory input. Psychol. Rev. 87: 175-189.

Horlington, M. (1968) A method for measuring acoustic startle response latency and magnitude in rats: Detection of a single stimulus effect using latency measurements. Physiol. Behav. 3: 839-844.

Ison, J. R., D. W. McAdam, and G. R. Hammond (1973) Latency and amplitude changes in acoustic startle reflex of the rat produced by variation in auditory prestimulation. Physiol. Behav. 10: 1035-1039. 
Kandel, E. R. (1978) Grass Lecture Monograph I: A CellBiological Approach to Learning, Society for Neuroscience, Bethesda, MD.

Kawamura, K. (1975) The pontine projection from the inferior colliculus in the cat. An experimental anatomical study. Brain Res. 95: 308-322.

Konig, J. F. R., and R. A. Klippel (1963) The Rat Brain, Williams and Wilkins Co., Baltimore, MD.

Kudo, M. (1981) Projections of the nuclei of the lateral lemniscus in the cat: An autoradiographic study. Brain Res. 221: $57-69$.

Kuypers, H. G. J. M., and V. A. Maisky (1975) Retrograde axonal transport of horseradish peroxidase from spinal cord to brain stem cell groups in the cat. Neurosci. Lett. 1: 9-14.

Landis, C., and W. Hunt, eds. (1939) The Startle Paradigm, Farrar and Rinehart, New York.

Larsson, L. E. (1956) The relationship between startle reaction and the non-specific EEG response to sudden stimuli with a discussion on the mechanism of arousal. Electroencephalogr. Clin. Neurophysiol. 8: 631-644.

Leitner, D. S., A. S. Powers, and H. S. Hoffman (1980) The neural substrate of the startle response. Physiol. Behav. 25: 291-297.

Leitner, D. S., A. S. Powers, G. L. Stitt, and H. S. Hoffman (1981) Midbrain reticular formation involvement in the inhibition of acoustic startle. Physiol. Behav. 26: 259-268.

Martin, G. F., A. O. Humbertson, Jr., L. C. Laxson, W. M. Panneton, and I. Tschismadia (1979) Spinal projections from the mesencephalic and pontine reticular formation in the North American opossum: A study using axonal transport techniques. J. Comp. Neurol. 187: 373-400.

Palkovitz, M., and D. Jacobowitz (1974) Topographical atlas of catecholamine and acetylcholinesterase-containing neurons in the rat brain. II. Hindbrain (mesencephalon, rhombencephalon). J. Comp. Neurol. 157: 29-42.

Peterson, B. W. (1979) Reticulospinal projections to spinal motor nuclei. Annu. Rev. Physiol. 41: 127-140.

Peterson, B. W., R. A. Maunz, N. G. Pitts, and R. G. Mackel (1975) Patterns of projection and branching of reticulospinal neurons. Exp. Brain. Res. 23: 333-351.

Peterson, B. W., N. G. Pitts, and K. Fukushima (1979) Reticu- lospinal connections with limb and axial motoneurons. Exp Brain Res. 36: 1-20.

Pfeiffer, R. R. (1966) Classification of response patterns of spike discharge for units in the cochlear nucleus: Tone burst stimulation. Exp. Brain Res. 1: 220-235.

Prosser, C. L., and W. S. Hunter (1936) The extinction of startle responses and spinal reflexes in the white rat. Am. J. Physiol. 17: 609-618.

Remmel, R. S., R. D. Skinner, and L. B. Minor (1980) Eighth nerve activation of cat pontine reticular neurons which project in or near the ascending medial longitudinal fasciculus. Exp. Neurol. 70: 706-711.

Szabo, I. (1965) Analysis of the muscular action potentials accompanying the acoustic startle reaction. Acta Physiol. Acad. Sci. Hung. 27: 167-178.

Szabo, I., and K. Hazafi (1965) Elicitability of the acoustic startle reaction after brain stem lesions. Acta Physiol. Acad. Sci. Hung. 27: 155-165.

Tohyama, M., K. Sakai, D. Salvert, M. Touret, and M. Jouvet (1979) Spinal projections from the lower brain stem in the cat as demonstrated by the horseradish peroxidase technique. I. Origins of the reticulospinal tracts and their funicular trajectories. Brain Res. 173: 383-403.

Warr, W. B. (1966) Fiber degeneration following lesions in the anterior ventral cochlear nucleus of the cat. Exp. Neurol. 14: 453-474.

Warr, W. B. (1969) Fiber degeneration following lesions in the posteroventral cochlear nucleus of the cat. Exp. Neurol. 23: 140-155.

Willott, J. F., A. Shnerson, and G. P. Urban (1979) Sensitivity of the acoustic startle response and neurons in subnuclei of the mouse inferior colliculus to stimulus parameters. Exp. Neurol. 65: 625-644.

Wilson, V., and M. Yoshida (1969) Comparison of effects of stimulation of Deiters' nucleus and medial longitudinal fasciculus on neck, forelimb and hindlimb motoneurons. J. Neurophysiol. 32: 743-758.

Wilson, V., M. Yoshida, and R. H. Schor (1970) Supraspinal monosynaptic excitation and inhibition of thoracic back motoneurons. Exp. Brain Res. 11: 282-295. 